\title{
Reply from Authors
}

\section{Response to the letter to the editor by Dr Waldinger et al: Hardy Weinberg Equilibrium in Genetic PE Research Remains Critical to Avoid Misinterpretation}

\author{
Emin Ozbek, Ali I. Tasci, Volkan Tugcu, Yusuf O. Ilbey, Abdulmuttalip Simsek, Levent Ozcan, Emre C. Polat, Vedat Koksal \\ Correspondence to: Dr Emin Ozbek, Bezm-i Alem Valide Sultan Vakif Gureba Research and Education Hospital, Depart- \\ ment of Urology, Istanbul 34095, Turkey. \\ Fax:+90-212-6217-580_E-mail:ozbekemin@hotmail.com
}

Asian Journal of Andrology (2009) 11: 525; doi: 10.1038/aja.2009.34

Dear Editor;

We have read the article by Waldinger et al [1]. First of all, once again we do apologise for the mistake in our article regarding a possible asssociation of the 5-HTTLPR gene polymorphism and lifelong premature ejaculation (PE) in Turkish men. Previously, the total number of patients and controls had been mistakenly written as ' 70 ' instead of ' 69 '. The percentage of $\mathrm{L} / \mathrm{S}$ and $\mathrm{S} / \mathrm{S}$ had also been written mistakenly $53 \%$ and $28 \%$ instead of $54 \%$ and $29 \%$, respectively. In addition, the number of ' $\mathrm{S}$ ' allele ' 74 ' should be corrected as '77' in Table 1. 'The $\mathrm{S}$ allele of the 5-HTTLPR gene was significantly more frequent in PE patients than in controls $(P<0.025)^{\prime}$ expression should be added to the 'Results' section of the study. No change has been applied on the other sections (introduction, material and methods, and discussion) of the study.

The other criticised issue is the statistical method used in our study. Statistical analyses were performed by an expert statistician in our study. All the statistical analyses of the groups were carried out again and the results of statistical analyses were found to be similar to previous values. Nevertheless, in our study results were statistically significant when genotype groups were compared according to $\chi^{2}$-test. Also, Hardy-Weinberg equilibrium test is pivotal for this kind of laboratory DNA testing and it can be used to generalize results of a study population to all population. There is a homogen distrubition in the control group of our study but not in the study group.

When to consider if our study is the first real DNA study showing an association between the intravaginal ejaculation latency time (IELT) in men with lifelong PE and 5-HTTLPR polymorphism, we have to point out that our study was received in 23 April 2008 and was accepted in 20 July 2008 by your journal. A similar study regarding the issue, performed by Janssen et al., was published in October 2008 (e-pub), latter than our study. Of course some authors also reported that high prevalance of PE in family members of men with lifelong PE, but these are only clinical observations which are not DNA-based molecular genetic studies.

\section{References}

1 Waldinger MD, Janssen PKC, Schweitzer DH. Hardy Weinberg Equilibrium in Genetic PE Research Remains Critical to Avoid Misinterpretation. Asian J Androl 2009; 11: 524. 